a few doublets. Nos. $7^{22}$ and 723 are charming patterns in snow architecture.

November $30 .-$ Clouds rather thin stratus and nimbus. Crystal types wholly tabular of both open and stellate structure (Fig. 2, Nos. 730-737).

Among the seven forms of this date we find much to admire in the perfect beauty and symmetry of Nos. 73 I-734. The beautiful starfish design exhibited by No. 73.5 is somewhat rare. It is noteworthy that Prof. S. Squinabol, of the University of Padua, made drawings of a snow crysta found in Genoa in 1887 that closely resembles this latter one. The star with long slender rays deposited during this same storm, on November 26 (see No. 712), also closely resembles one figured by Squinabol in his work "La Navigata." No. 737 is another form that closely resembles some of those secured by other observers; it is very similar to some of the photomicrographs secured by Dr. Neuhaus, of Berlin, during the winter of 1893 , and published in Dr. G. Hellmann's work.

December 4.-Clouds stratus, with detached running masses of low nimbus; probably high cirro-stratus above these. The western portion of this cold southern storm
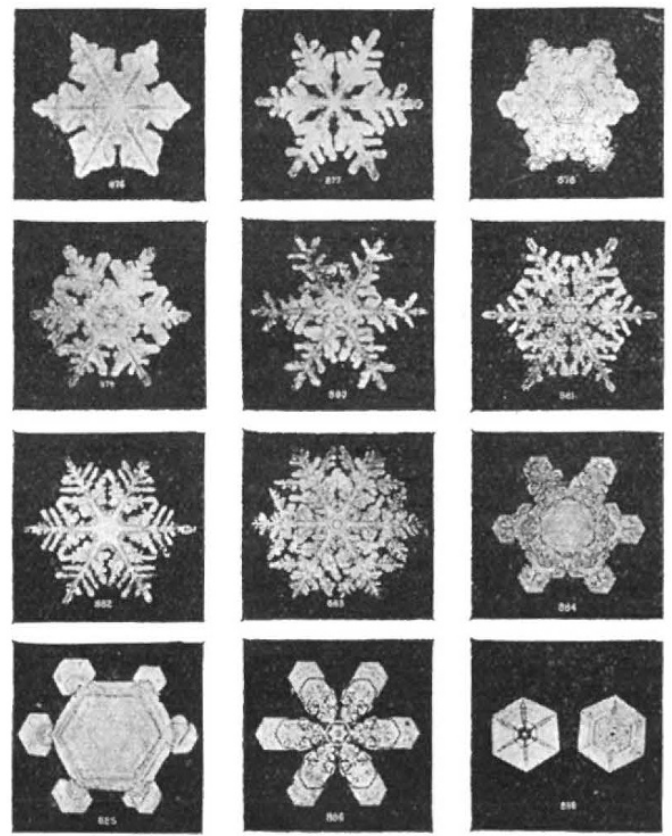

Fig. 6.-Nos, $876=888$.

furnished a great number of forms of snow crystals that were in general rather small and compact.

The rare beauty of Nos. 745,748 (Fig. 3) will appeal to all; crystallographers will find much of interest in No. 749.

I902, January 5.-The clouds of the western edge of the storm of January 5 , 1902, furnished a large and splendid set of forms. Nos. $783,785,786$, and 788 (Fig. 4) are exquisite examples of the frail, branching type of crystals. No. 785 is so rarely beautiful that Mr. Bentley describes it as the peer of any in his whole collection.

January.12.-Clouds obscured by heavy srlowfall. A long series of magnificent snow crystals was secured from the clouds of the south-west-central portion of the storm or blizzard of January 12 (see Nos. $816-824$, Fig. 5). The snow, as usual whenever it comes from the central-western portion of a storm, consisted of a great variety of types both columnar and tabular, but as the storm's central portion passed farther to the east, during the afternoon of January 12, the columnar forms ceased to be deposited. Nos. 818, $82 x$ and 822 possess much beauty of design and perfection of form.

February 8.-Clouds stratus and nimbus; probably high cirro-stratus superimposed above them. A continuation of the storm of February 7 , and its increase in rigour furnished more forms than were ever before secured by $\mathrm{Mr}$. Bentley from any one storm. The beautiful branching crystals, Nos. $88 \mathrm{I}$ and 883 (Fig. 6), portray, in general, the characters of the forms that successively replaced both the solid tabular and columnar forms, as the western edge of the storm came nearer. No. 884 exhibits a most interesting phase of crystallic evolution; it is composed of four contiguous points, or rather portions, and two somewhat stunted portions, also similar to each other, but differing widely from the other four. No. 885 shows two overlapping additions to two of the points, thus rendering it of more than usual interest, and presenting us with another seemingly unsolvable problem in crystallography.

In concluding this mention of individual forms, it is worthy of note that, as during previous winters, occasionally single individual crystals, and more rarely larger numbers of such, produced during the storms of this winter, resembled closely, in outline or interior details, or oddity, one or more of the individual forms found among the snows of previous winters. The recurrence of similar types, after perhaps long intervals of time have elapsed, is a phenomenon of great interest.

In conclusion, it may be worth noting that by the addition of more than 200 plates during the past winter, the number of individual photomicrographs of crystals in Mr. Bentley's collection is brought up to somewhat more than Iooo, no two of which are alike. This completes also his seventeenth year of photographic work among the snow crystals.

\section{DR. A. A. COMMON, F.R.S.}

$\mathrm{T}$ was with deep regret that the news of the sudden death of Dr. Common had to be announced in the last number of this Journal. Dr. Common was so hale and hearty that it came as a great shock to his friends to find that he was no more, and his loss is felt not only by a great circle of friends, but by the astronomical world at large. Born in $184 x$, August 7 , Dr. Andrew Ainslie Common was by profession an engineer, but quite at an early date he turned his attention to astronomy. In 1874 he became the possessor of a $5^{\frac{1}{2}}$-inch refractor, and three years later of an 18 -inch reflector by Calver. It was evidently the use of the latter instrument which sowed the seed for his later important researches in the making and silvering of both large and small mirrors. An idea of his remarkable energy and success in the grinding and silvering of mirrors can be gathered from the following list of large reflectors in use which he referred to in his presidential address to Section A (Department of Astronomy) of the British Association in Igoo. This list only referred to reflectors of $2 \mathrm{ft}$. 6in. and upwards, and out of the nine given five were from his own workshop.

\section{Reflectors of $2 \mathrm{ft} .6 \mathrm{in}$. and upwards.}

\begin{tabular}{|c|c|c|c|c|c|}
\hline Lord Rosse & $\cdots$ & $\cdots$ & $\cdots$ & $\cdots$ & \\
\hline Dr. Common & $\ldots$ & $\ldots$ & $\cdots$ & $\ldots$ & $\cdots$ \\
\hline Melbourne & $\ldots$ & $\ldots$ & ... & $\ldots$ & $\ldots$ \\
\hline Paris $\quad \ldots$ & . & $\ldots$ & 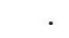 & $\ldots$ & $\ldots$ \\
\hline Meudon $\quad \ldots$ & $\cdots$ & $\ldots$ & $\ldots$ & $\ldots$ & $\cdots$ \\
\hline Solar Physics & Obser & atory & (Con & on) & $\cdots$ \\
\hline Crossley (Lick & Con & non) & $\cdots$ & $\cdots$ & $\therefore$ \\
\hline Greenwich (Co & mmor & & $\ldots$ & $\cdots$ & $\cdots$ \\
\hline Solar Physics & Obsen & atory & (Com & & . \\
\hline
\end{tabular}

His knowledge of engineering was a valuable adjunct in the designing and construction of the mountings for his large mirrors. Dr. Common paid great attention to this latter question, for on it depended to a very great extent their efficiency and utilisation. He eliminated the "tube" by substituting a light framework of iron which reduced air currents to a minimum; adopted a new method to prevent the mirror being strained; mounted large mirrors equatorially by the ingenious device of reducing the friction of the moving parts by floating them in mercury; designed 
and used successfully a slipping plate for use in the principal focus for photographic and visual purposes.

Not only was his time chiefly devoted to the construction of these astronomical instruments, but he turned them to great advantage by showing what could be done with them. Among the most noteworthy of these attainments was the magnificent photograph of the nebula of Orion which he secured in 1883 , and for which he won the gold medal of the Royal Astronomical Society. Nebulæ, star clusters, \&c., all came under his keen eye, and his researches not only demonstrated the cumulative effect of the photographic film, but showed that a new field of astronomical work was dawning by the employment of reflectors for long exposure photography.

More recently Dr. Common, among other things, turned his attention to the improvements in telescopic gun sights, and in this direction his loss will be keenly felt. He became a fellow of the Royal Astronomical Society in 1876 , received the gold medal in 1884 , and was president in $1895-96$. He was elected a fellow of the Royal Society in $188_{5}$, and was an honorary LL.D. of St. Andrews.

Jovial, good-hearted, good-natured, and generous beyond degree in distributing his mirrors to those who would use them, all his friends join with the widow, son and three daughters whom he has left behind in mourning the loss of a personal friend.

Will.iAM J. S. LOCKYer.

\section{PROF. C. A. BJERKNES.}

I N Nature of May 28 mention was made of the death of Prof. C. A. Bjerknes, of the University of Christiania, at the age of seventy-eight.

Thoush occupying the chair of pure mathematics, it was to applied mathematics, and especially to hydrodynamics, that Bjerknes devoted the greater part of his attention and study. He studied mathematics at the University of Göttingen early in the " fifties," his teachers including Riemann, who lectured on Abelian functions to a class of three only-Schering, Bjerknes and Dedekind-presumably between I8 1 , when Riemann obtained the doctorate, and 1859 , when he was appointed ordinary professor, also Lejeune Dirichlet, who lectured to Schering and Bjerknes in $1855^{-56}$, and who proposed to them the problem of the ellipsoid in a steady fluid current. Solutions were given by both Schering and Bjerknes, but it was not until 1873 that Bjerknes completed his work on the problem of the general motion of an ellipsoid in fluid.

Bjerknes was at an early date attracted by the problem of replacing action at a distance by action of an intervening medium, and he exhibited considerable originality in the energy with which he took up the advancement of a doctrine which at that time received iittle support. The discovery that a sphere could move through a perfect liquid without retardation having shown that the existence of an ether does not involve a violation of Newton's first law, Bjerknes set to work to investigate the forces acting between two spheres moving in liquid, and in particular he developed the notion of "pulsating" spheres, i.e. spheres fluctuating periodically in volume, finding that between such spheres attractions and repulsions exist, obeying the law of the inverse square, and their sense being dependent on whether the phases are the same or opposite. The discussion of all the terms entering in to the expressions for the forces was not completed until a comparatively late date, and in the meanwhile dynamical theories of physical phenomena have developed in other quarters, and ethers differing in their properties from ordinary matter, and in particular from matter in a fluid state, have come into existence. But another interest was aroused in these hydrodynamical attractions and repulsions by the experiinental verifications of the results of the theory which were successfully carried out by both Prof. C. A. Bjerknes and his son, and of which we hope to give a fuller account shortly. These experiments were commenced in 1875 , using rough and ready methods, but the apparatus have been gradually improved, and a number of papers on the subject were published, chiefly in the period $1878-1880$, by Bjerknes and Schiötz in the Christiania Forhandlinger.

Among Bjerknes's other writings we note the biographical notice "Niels Henrik Abel; tableau de sa vie et de son action scientifique," published at Paris in I885. Prof. V. Bjerknes has for many years collaborated with his father, and the second volume of his "Vorlesungen nach C. A. Bjerknes' Theorie" only appeared quite recently.

G. H. BRYAN

\section{NOTES.}

Mr. BALFour has accepted the presidency of the British Association for the meeting to be held at Cambridge in 1904 .

Prof. RAY LANkESTFR has been elected a Foreign Associate of the National Academy of Sciences, Washington, and a member of the American Philosophical Society, Philadelphia.

We learn from the Paris correspondent of the Times that a monument, which has been erected by public subscription to the memory of Pasteur, was unveiled at Chartres on Sunday. This memorial specially commemorates the services of the great bacteriologist to agriculture by his discovery of a specific for anthrax, which resulted from a long series of experiments undertaken at a local farm. The principal feature of the monument is a high relief, which represents Pasteur and his assistants at work. It is the design of Dr. Paul Richer, who, besides being a member of the Acadumy of Medicine, is a distinguished sculptor.

A Reuter message from Simonstown, dated June 9, states that the German Antarctic ship Gauss arrived there on Tuesday morning after a successful year's work in the South Polar regions. She will remain there for three weeks to refit, and will then sail for home. On sailing from Cape Town the Gauss called at Kerguelen Island, and landed a party, which reached the floating ice on February 14, 1902. The ship was ice-bound on February 22 in lat. $66 \frac{1}{2}$, long. 9o. New land was discovered, which was named the Emperor William II. Land. This was covered with ice, with the exception of an inactive volcano. The expedition was ice-bound here for almost a year, and many scientific investigations were carried out during this period. The ship left the ice on April 8 and proceeded to Durban, passing Kerguelen Island, and calling at St. PauI and New Amsterdam Islands. The members of the expedition enjoyed good health, there being no case of sickness, accident, or death during the whole cruise. Prof. Drygalski speaks in the highest terms of the vessel's behaviour, both in the sea and in the ice.

The Hanbury gold medal has this year been awarded to M. Eugène Collin, École de Pharmacie, Paris.

A taislet placed on the wall of Coate House, near Swindon, Wilts, the birthplace of Richard Jefferies, was unveiled by Prof. N. Story Maskelyne on June 6 .

No. I 754, voL. 68] 